\title{
Effective lipid extraction from undewatered microalgae liquid using subcritical dimethyl ether
}

\author{
Quan Wang, Kazuyuki Oshita* and Masaki Takaoka
}

\begin{abstract}
Background: Recent studies of lipid extraction from microalgae have focused primarily on dewatered or dried samples, and the processes are simple with high lipid yield. Yet, the dewatering with drying step is energy intensive, which makes the energy input during the lipid production more than energy output from obtained lipid. Thus, exploring an extraction technique for just a thickened sample without the dewatering, drying and auxiliary operation (such as cell disruption) is very significant. Whereas lipid extraction from the thickened microalgae is complicated by the high water content involved, and traditional solvent, hence, cannot work well. Dimethyl ether (DME), a green solvent, featuring a high affinity for both water and organic compounds with an ability to penetrate the cell walls has the potential to achieve this goal.

Results: This study investigated an energy-saving method for lipid extraction using DME as the solvent with an entrainer solution (ethanol and acetone) for flocculation-thickened microalgae. Extraction efficiency was evaluated in terms of extraction time, DME dosage, entrainer dosage, and ethanol:acetone ratio. Optimal extraction occurred after 30 min using $4.2 \mathrm{~mL}$ DME per $1 \mathrm{~mL}$ microalgae, with an entrainer dosage of $8 \%$ at 1:2 ethanol:acetone. Raw lipid yields and its lipid component (represented by fatty acid methyl ester) contents were compared against those of common extraction methods (Bligh and Dryer, and Soxhlet). Thermal gravimetry/differential thermal analysis, Fourier-transform infrared spectroscopy, and $\mathrm{C} / \mathrm{H} / \mathrm{N}$ elemental analyses were used to examine differences in lipids extracted using each of the evaluated methods. Considering influence of trace metals on biodiesel utilization, inductively coupled plasma mass spectrometry and inductively coupled plasma atomic emission spectroscopy analyses were used to quantify trace metals in the extracted raw lipids, which revealed relatively high concentrations of $\mathrm{Mg}, \mathrm{Na}, \mathrm{K}$, and $\mathrm{Fe}$.

Conclusions: Our DME-based method recovered $26.4 \%$ of total raw lipids and $54.4 \%$ of total fatty acid methyl esters at first extraction with remnants being recovered by a 2nd extraction. In additional, the DME-based approach was more economical than other methods, because it enabled simultaneous dewatering with lipid extraction and no cell disruption was required. The trace metals of raw lipids indicated a purification demand in subsequent refining process.
\end{abstract}

Keywords: Lipids, DME, Liquid-liquid subcritical extraction, Fames profile, Trace metals

*Correspondence: oshita@epsehost.env.kyoto-u.ac.jp

Department of Environmental Engineering, Graduate School of Engineering, Kyoto University, Cluster C, Kyoto Daigaku-Katsura, Nishikyo-ku, Kyoto 615-8540, Japan

\section{Background}

The development of renewable energy technologies has advanced in response to an ever-increasing demand for fossil fuels and global warming caused by $\mathrm{CO}_{2}$ emissions from their combustion [1-3]. Biodiesel produced from microalgae is considered a promising substitute for fossil 
fuels $[4,5]$ because microalgae boast a high growth rate and high lipid content. These features enable a high rate of carbon fixation with the potential for highly efficient biodiesel production. Furthermore, microalgae can be easily grown on non-arable land, which avoids competition with food production [6-8].

Biodiesel production from microalgae consists primarily of microalgae cultivation, harvesting, lipid extraction, and transesterification [9]. However, harvesting and lipid extraction are substantial bottlenecks in the development of an energy-efficient and cost-effective process for conversion of microalgae to biodiesel [10, 11]. Microalgae typically exhibit small cell size $(5-50 \mu \mathrm{m})$ and low density $(0.5-5 \mathrm{~g} / \mathrm{L})$ in growth media. These factors make it difficult to directly extract lipids without some form of harvesting pretreatment [12, 13]. In a typical process, microalgae suspensions are first thickened via gravity sedimentation, flocculation, or flotation to obtain slurry with a biomass content of 3-7\%. This concentrated slurry is then mechanically dewatered by filtration or centrifugation to obtain cake with a biomass content of $10-25 \%$. In a final step, the cake is thermally dried to a biomass content of $>90 \%[5,14,15]$.

Extraction of lipids is simpler from a completely dry microalgae sample than from a sample that has just been dewatered. A Soxhlet extraction with n-hexane obtained a $45 \%$ (dry base) yield of lipid from dried Schizochytrium limacinum [16]. Jie et al. [17] used ethanol to extract 48\% (dry base) lipid from dried Synechocystis PCC 6803. Supercritical extraction using $\mathrm{CO}_{2}$ and ethanol has been used to obtain a $34 \%$ (dry base) yield of lipid from dried S. limacinum powder [16]; an 18.1\% (dry base) lipid yield from dried Chlorella spp. powder was obtained using a mixed extraction solvent of methanol:ethyl acetate at a volume ratio of 2:1 [18].

However, drying is an energy-intensive process. Removal of $1 \mathrm{~kg}$ of water from mechanically dewatered microalgae ( $20 \%$ biomass) by thermal drying requires $3560 \mathrm{~kJ}$ of energy input, rendering the net energy balance negative [5]; thus, the energy output from the extracted biodiesel is less than the energy needed to produce the biodiesel [3].

Energy consumption during biodiesel production from thermally dried microalgae is nearly 4000-fold greater than energy consumption during biodiesel production from merely mechanically dewatered microalgae ( $\sim 20 \%$ biomass; wet microalgae) [19]. Hence, a positive net energy balance can be achieved without thermal drying $[3,13]$. Therefore, several investigations have focused on lipid extraction from wet microalgae. For example, Lakshmikandan [20] used a mixed solvent of hexane and isopropanol $(3: 2 \mathrm{v} / \mathrm{v})$ to extract lipids from centrifugation-harvested Chlorella vulgaris (biomass content $\sim 8.9 \%$ ) and obtained a maximum lipid yield of $22.5 \%$ (dry base). Ethyl acetate has been used to extract lipids from wet Isochrysis galbana (5\% biomass) at a yield of $17.6 \%$ [21]. Among six evaluated solvent systems, isopropanol:hexane $(2: 1 \mathrm{v} / \mathrm{v})$ was the most effective in extraction of lipids from wet Scenedesmus obliquus (20\% biomass), affording a $7.8 \%$ lipid yield (dry base) [3]. A solvent system of chloroform:methanol:sulfuric acid $(1: 1: 0.05 \mathrm{v} / \mathrm{v})$, combined with microwave irradiation, was used to obtain a $19.0 \%$ (dry base) yield of lipids from centrifuged Chlorella pyrenoidosa (water content, $80 \mathrm{wt} \%$ ) [22].

Because dewatering via centrifugation or filtration requires considerable energy compared to the thickening process [23], direct extraction of lipids from thickened microalgae would significantly improve the net energy gain. Yet with the water content of microalgae increasing, more solvent may be needed to match the phase mass transfer equilibrium, and the cost for the increased solvent could be considerable; thus, it is necessary to achieve the above objectives without increasing solvent consumption. Liquid dimethyl ether (DME) is a promising solvent for extraction of lipids from thickened microalgae. Liquid DME is partially miscible with water (7-8 wt\% DME; room temperature) and features a high affinity for organic compounds. Thus, DME is suitable for extraction of lipids from wet biomass samples with simultaneous dewatering. This combined process represents considerable energy savings $[24,25]$. In addition, DME is a gas under ambient conditions; thus, it can be easily liquefied at $0.51-0.59 \mathrm{MPa}$ and room temperature $\left(20-25^{\circ} \mathrm{C}\right)$. The low boiling point of DME (i.e., $-25^{\circ} \mathrm{C}$ ) allows it to be easily removed via evaporation for recycling/reuse $[25,26]$.

DME has been successfully applied for extraction of lipids and removal of moisture from dewatered biomass, including sludge [25, 27], cattle manure [28], microalgae [29] and vegetables [30]; however, its use with merely thickened samples has not been studied. This is largely because its low polarity results in immiscibility with microalgae suspended in water. Although DME can absorb a small fraction of water, as mentioned above, greater proportions of water result in discrete aqueous and organic layers, thereby preventing DME from coming into close contact with microalgae cells. This effect is more noticeable with marine algae, because the polarity of the algal slurry is enhanced by dissolved salts. Although not the most economical approach, one solution involves the use of large volumes of DME [31]; specifically, a 167:1 weight ratio of DME to microalgae (dry base) was necessary for extraction of lipids from a sample containing 9\% solids. Another potential solution involves the use of a solvent with infinite miscibility in water for 
adjustment of DME polarity. Adjustment of the cosolvent ratio allows DME to be completely mixed with water. This type of additive is regarded as an entrainer, and has been shown to improve the efficiency of supercritical fluid extraction [32, 33].

The liquified DME also has been reported to be a kind of green solvent [34]. Very often, challenges with conventional solvents arise due to their toxicity and impact on the environment. And the DME received significant attention as an alternative solvent due to its nontoxic, environmentally friendly, easier to transport, potentially renewable and relatively cheap [35]. Even DME is safety for food industrials, since the residual DME present in food products is expected to be significantly below the lowest no-effect limit and in some cases below the detection limit which makes the extracted material potentially safe for consumption [36].

The novelty of this study was to develop a microalgal lipid extraction technology based on DME subcritical extraction, which was suited for undewatered samples. Since the subcritical extraction was realized, the operation condition (0.51-0.59 MPa, room temperature) was easier to be achieved with less operating costs and security risks than the supercritical fluid extraction (SCF) [37], while it retained SCF's advantages (higher selectivity, lower extraction time, and non-requirement of a follow-up separation) [37]. And the DME method in this study also eliminated energy or chemicals consumption of additional cell disintegration usually used in other methods [38]. In addition, compared with the formerly reported DME method [29], this study modified it to be applied to undewatered microalgae ( $~ 95 \%$ of water content) and further reduced the consumption in the sample pretreatment, while the DME dosage was not increased. Furthermore, this technology made microalgae residues after lipid extraction the low moisture content by simultaneously dewatering/drying, and hence had a potential to be used as solid biofuel. This combined process represented considerable energy savings.

Here, liquefied DME was used to extract lipids from $\mathrm{AlCl}_{3}$-flocculated Nannochloropsis oculata (solid content $18.3 \mathrm{~g} / \mathrm{L}$ ). A suitable entrainer for DME was identified among ethanol, dimethyl sulfoxide (DMSO), acetone, and tetrahydrofuran (THF). Extraction performance was evaluated with respect to changes in extraction time, DME dosage, entrainer composition, and entrainer proportion in DME. The performance of our modified DME-based method was compared to the performances of Bligh and Dryer, and Soxhlet methods in terms of raw lipid yield, fatty acid yield, and $\mathrm{C} / \mathrm{H} / \mathrm{N}$ composition. For each method, extracted lipids were characterized by thermal gravimetry (TG)/differential thermal analysis (DTA),
Fourier-transform infrared spectroscopy (FTIR), and trace elemental analyses.

\section{Results and discussion \\ Entrainer screening for improved lipid extraction using DME}

Figure 2a shows the yields of extracted raw lipids and FAMEs using our DME-based method (25 mL DME for $8 \mathrm{~mL}$ of microalgae) with each of the four entrainers. The blank system yielded $14.4 \mathrm{mg} / \mathrm{g}$ (dry base) raw lipid. In contrast, 57.3, 16.4, 91.8 and $16.3 \mathrm{mg} / \mathrm{g}$ raw lipid were obtained with $2.5 \mathrm{~mL}$ of ethanol, DMSO, acetone, and THF, respectively. These results showed that both ethanol and acetone were effective entrainers, enhancing raw lipid yields by factors of 4.0 and 6.4 relative to the blank, respectively. DMSO and THF were less effective, producing only $\sim 1.1$-fold improvements in raw lipid yields. The proportions of FAMEs obtained also varied among entrainers. For example, the highest proportion of FAMEs $(62.0 \%)$ in the extracted raw lipid was obtained with the blank. Experiments incorporating THF yielded a similar value of $60.5 \%$. The FAME proportions obtained using ethanol, DMSO, and acetone were 48.0\%, 49.6\%, and $41.4 \%$, respectively. Notably, the yields of FAMEs (absolute value, Fig. 2a) obtained with ethanol $(27.4 \mathrm{mg} / \mathrm{g}$ $\mathrm{DB})$ and acetone $(37.9 \mathrm{mg} / \mathrm{g} \mathrm{DB})$ were much higher than those obtained with the blank $(8.9 \mathrm{mg} / \mathrm{g} \mathrm{DB})$, despite the smaller proportions. The solids contents (mainly containing microalgae cell residues and a small part of remaining salt) of microalgae samples after DME treatments using the four entrainers are shown in Additional file 1: Figure S1. The solids content of the blank increased to $19.4 \%$ after DME treatment of flocculation-thickened microalgae containing $\sim 95 \%$ water. Thus, water and lipids were extracted simultaneously from microalgae samples using liquefied DME and an entrainer. Accordingly, this process can be regarded as an effective dewatering method. However, the addition of an entrainer did not enhance dewatering. The solids contents of the acetone and THF groups were $20.4 \%$ and $20.7 \%$, which represented no significant improvements over the blank group. A slight reduction in solids content (17.2\%) was observed when using ethanol as the entrainer. The solids contents of samples treated with DMSO were only $12.5 \%$, demonstrating that DMSO was not an effective dewatering agent.

The FAME compositions of the various samples are shown in Additional file 1: Figure S2. No obvious differences were observed. For all five groups (blank and four entrainers), FAMEs in the extracted raw lipids were composed primarily of C16:0, C16:1, and C18:1n9c, representing $60-70 \%$ of the total FAMEs. The remaining FAMEs were distributed between $\mathrm{C} 4: 0$ and C24:1n9. 
These findings indicated that the entrainer did not affect the FAME composition of the extracted raw lipids.

Given the above results, ethanol and acetone, each of which significantly improved lipids yields with minimal effects on dewatering, were selected for further investigation as entrainers. DME has a low polarity (dielectric constant of 5.02) and is generally immiscible with water (dielectric constant of 78.54). However, hydrogen bonds formed between DME and water can result in partial miscibility [39], enabling DME to efficiently absorb water from microalgae [29]. In the present study, the amount of water in microalgae samples exceeded the miscibility limit of DME, which can only absorb $7-8 \mathrm{wt} \%$ water. Therefore, our mixtures of DME and microalgae separated into two liquid layers, preventing the close contact between DME and algal cells that is required for lipid extraction. The addition of ethanol (dielectric constant of 24.60) or acetone (dielectric constant of 21.01) changes the polarity of the organic phase [40], increasing its miscibility with water. Conversely, the addition of THF (dielectric constant of 7.52) did not improve lipid extraction because it precipitated out of the microalgae slurry (sea water) [41]. Among the four entrainers, DMSO had the highest dielectric constant of 47.00, implying good solubility in water and poor compatibility with DME. This latter feature explains the failure of DMSO to improve lipid extraction. Thus, the dielectric constant of an ideal entrainer should be neither excessively high nor excessively low.

\section{DME-based extraction with an ethanol-acetone entrainer}

The effects of extraction time on the lipid yields using our DME-based method are shown in Fig. 1a. Raw lipid yields increased with extraction time, reaching $0.0359 \mathrm{~g} / \mathrm{g}$ dry biomass after $10 \mathrm{~min}, 0.0871 \mathrm{~g} / \mathrm{g}$ dry biomass after $20 \mathrm{~min}$, and $0.1110 \mathrm{~g} / \mathrm{g}$ dry biomass after $30 \mathrm{~min}$. No further increases in yield were observed beyond $30 \mathrm{~min}$. The proportions of FAMEs in the extracted raw lipids ranged from 35.0 to $41.1 \%$. Changes in FAME proportions as a function of extraction time were not obvious. Similarly, the solids content of microalgae after extraction remained consistent between 10 and $45 \mathrm{~min}$. The lowest solids content of $18.3 \%$ was observed after $10 \mathrm{~min}$ of extraction; this increased to $20.2 \%$ after $45 \mathrm{~min}$. Thus, only $30 \mathrm{~min}$ was required to fully extract the raw lipids. Furthermore, the rates of FAME and non-FAME transfer to DME were similar. Therefore, dewatering by DMEbased extraction could be accomplished in a relatively short time (10 min).

Figure $1 \mathrm{~b}$ shows the effects of DME dosage. Raw lipid yield increased dramatically with the dosage of DME. Using $1.6 \mathrm{~mL} \mathrm{DME} / \mathrm{mL}$ microalgae yielded $0.0716 \mathrm{~g}$ raw lipid/g dry biomass. A DME dosage of $6.3 \mathrm{~mL} / \mathrm{mL}$ yielded $0.2333 \mathrm{~g}$ raw lipid/g dry biomass. At DME dosages as high as $6.3 \mathrm{~mL} / \mathrm{mL}$, the trend of increasing raw lipid yields with increasing DME dosage did not diminish. The proportions of FAMEs obtained with DME dosages of 1.6, 2.1, 2.5 and $3.1 \mathrm{~mL} / \mathrm{mL}$ were $37.1 \%, 40.6 \%$, $41.8 \%$, and $37.9 \%$, respectively. Thus, no significant differences in FAME proportions were observed as a function of DME dosage. However, when the DME dosages were increased to 4.2 and $6.3 \mathrm{~mL} / \mathrm{mL}$, the proportions of FAMEs decreased to $27.6 \%$ and $30.6 \%$, respectively. This effect can be attributed to diminishing returns. FAMEs become more difficult to extract as their concentrations in microalgae decrease. In contrast, residual non-FAME components were present; thus, the diminishing effect was less obvious. This hypothesis will be discussed in Sect. "Raw lipid yields and FAME profiles". Analysis of the solids contents of various samples after extraction revealed that water removal increased with DME dosage. At a DME dosage of $1.6 \mathrm{~mL} / \mathrm{mL}$, the solids content of the microalgae was $14.6 \%$; it increased to $24.9 \%$ with $6.3 \mathrm{~mL} / \mathrm{mL}$ DME. Increasing the DME dosage significantly improved raw lipid extraction with simultaneous dewatering. However, the reduced proportions of FAMEs at DME dosages exceeding $4.2 \mathrm{~mL} / \mathrm{mL}$ indicated a weakening effect at higher dosages.

Extraction performance as a function of entrainer dosage is illustrated in Fig. 1c. Raw lipid yield grew nearly linearly with increasing entrainer dosage (ethanol +acetone). An entrainer dosage of $2 \%$ (in DME) slightly enhanced raw lipid yield to $0.0271 \mathrm{~g} / \mathrm{g}$ dry biomass. At a dosage of $6 \%$, the yield was $0.0912 \mathrm{~g} / \mathrm{g}$; a dosage of $12 \%$ entrainer yielded $0.1646 \mathrm{~g} / \mathrm{g}$ raw lipids. Within an entrainer range of $2 \%-8 \%$, the amounts of extracted FAMEs (at a constant proportion of $~ 37.1 \%$ ) increased with increasing entrainer dosage. However, FAME proportions decreased to $27.4 \%$ at an entrainer dosage of $12 \%$. The effects on dewatering were minimal, and the observed solids content remained stable at $19.9 \%$. Thus, FAME proportions decreased at entrainer dosages exceeding $10 \%$, while raw lipid yields continued increase. As a result, the benefit to FAME extraction by increasing the entrainer dosage from 8 to $12 \%$ was limited; $8 \%$ or $10 \%$ entrainer was suitable for the DME-based extraction of FAMEs.

The influence of ethanol:acetone ratio on lipid yield is shown in Fig. 1d. Higher raw lipid yields were obtained at lower ratios of ethanol to acetone. Differences between lipid yields obtained at ratios of 1:4 to $1: 2$ were minimal, with yields of approximately $0.1581 \mathrm{~g} / \mathrm{g}$. Raw lipid yield began to decrease at a ratio of 1:1; yields of 0.1241 and $0.1278 \mathrm{~g} / \mathrm{g}$ were obtained for ratios of $3: 1$ and 4:1, respectively. The effects of this ratio on FAME proportions and 

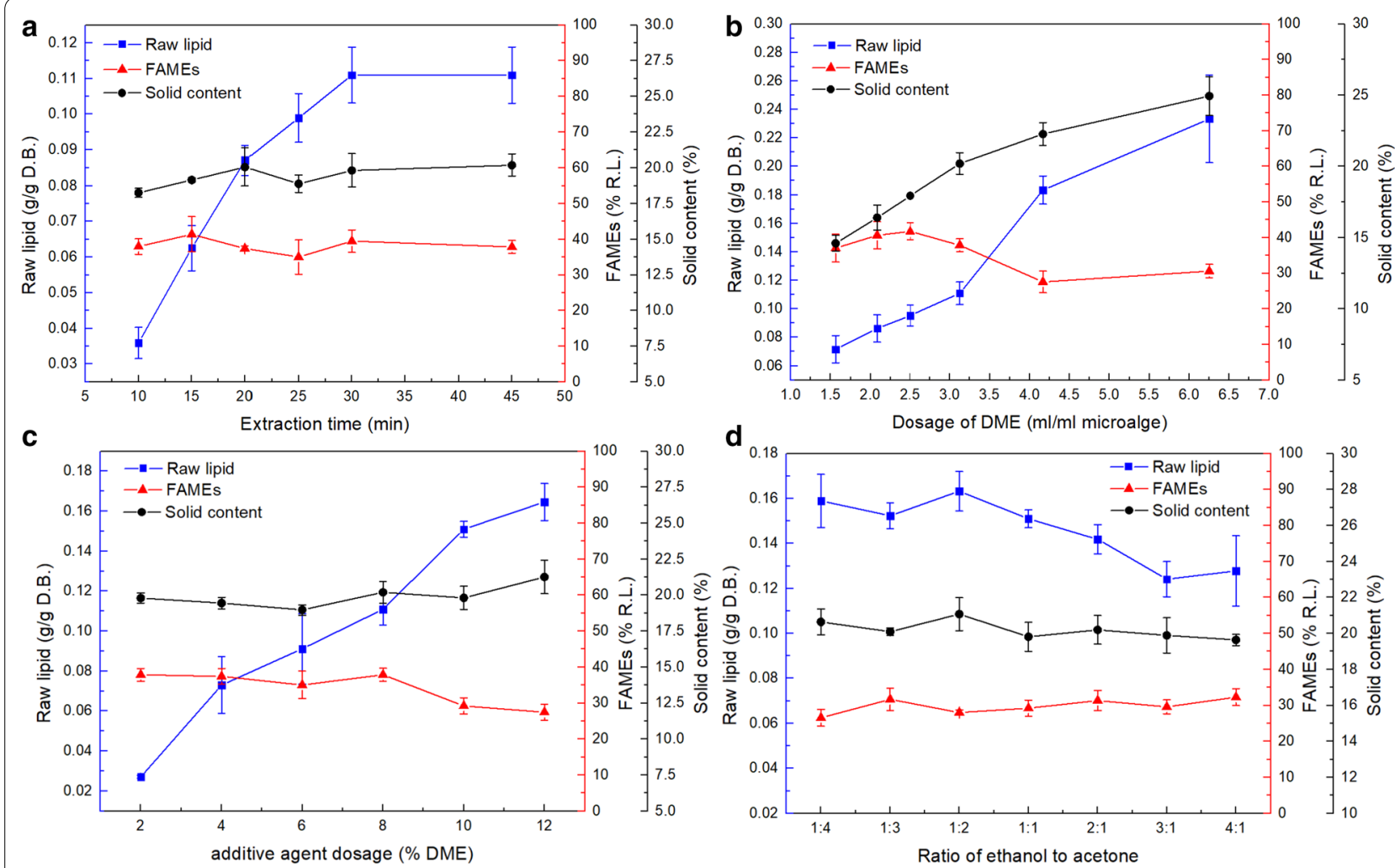

Fig. 1 Lipid extraction and dewatering using our DME-based method with an entrainer of ethanol-acetone. Influences of $\mathbf{a}$ extraction time, $\mathbf{b}$ DME dosage, $\mathbf{c}$ entrainer dosage, and $\mathbf{d}$ ethanol:acetone ratio on raw lipids yield are shown
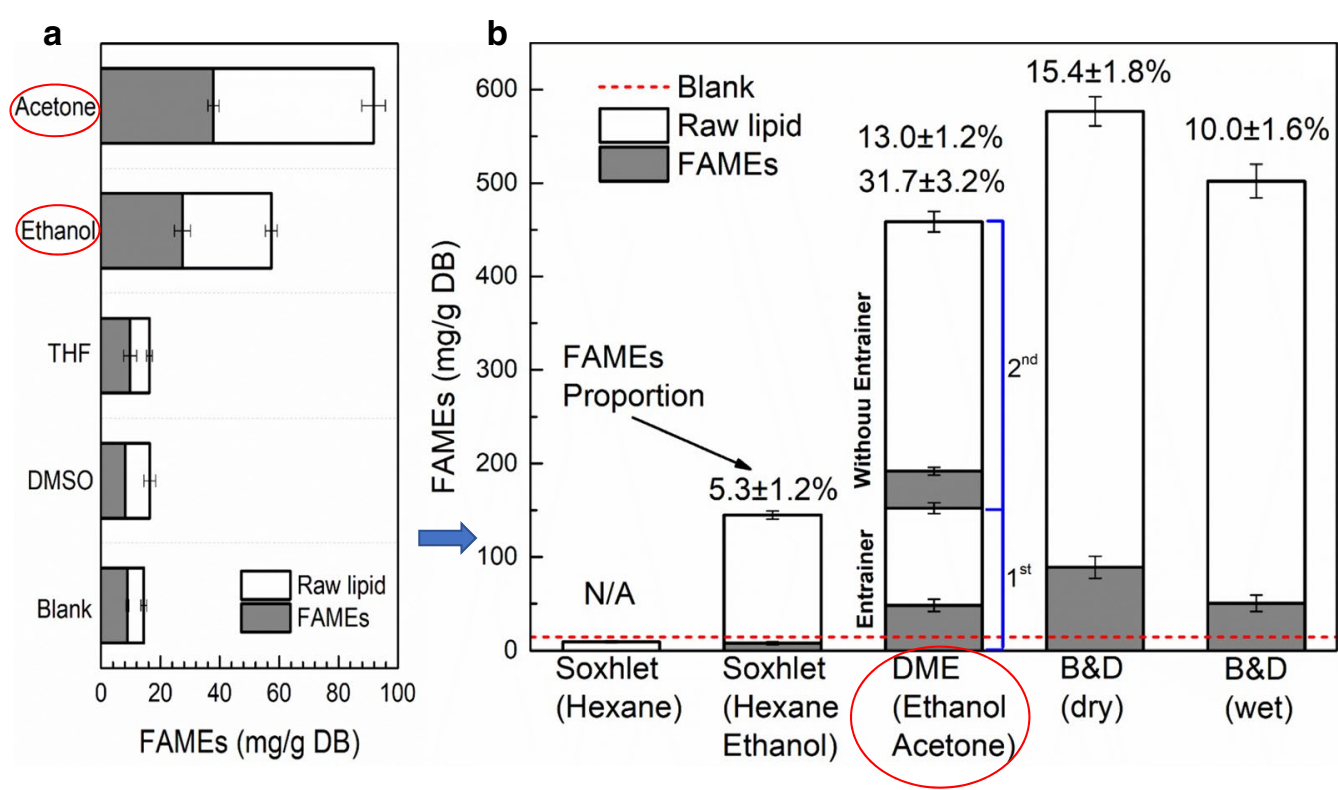

Fig. 2 Raw lipid yields with FAMEs a entrainer screening, b comparison with conventional methods 
solids contents were not obvious; they ranged from 26.5 to $32.3 \%$ and from 19.6 to $21.1 \%$, respectively. The greatest yields of both raw lipids and FAMEs were obtained at relatively low ratios (1:3 or 1:2) of ethanol to acetone.

Generally, raw lipids extracted from microalgae contain non-polar lipids (e.g., triglyceride, wax esters, and steryl esters), polar lipids (e.g., phospholipid and glycolipid), free fatty acids, sterols, proteins, hydrocarbons, pigments, and other algal products $[1,42,43]$. Because these components differ in polarity, the extraction process of each is influenced by solvent polarity. Shin et al. [44] used various types of solvents to extract lipids from microalgae; they observed the lowest lipid yield with hexane, a non-polar solvent. In contrast, more lipids were extracted by a medium polarity solvent, such as isopropanol. The greatest number of lipids was extracted using a mixture of hexane and isopropanol. The advantages of combining non-polar and polar solvents in the extraction of lipids have been demonstrated in previous reports $[3,45]$. In this study, the low polarity of DME allowed strong interactions with neutral lipids. The addition of ethanol and acetone enhanced interactions with polar lipids. This effect is ultimately responsible for the enhanced raw lipid yields and FAME proportions described above. Water in flocculated microalgae acts as a barrier between intracellular lipids in cells and DME $[6,40]$. The miscibility of entrainers with water was crucial to achievement of efficient lipid extraction with minimal DME consumption. In addition, the solids contents of samples increased to $\sim 20 \%$ after DME treatment, indicating a simultaneous dewatering effect.

\section{Comparison of DME-based extraction using an entrainer with Bligh and Dryer, and Soxhlet extraction methods Raw lipid yields and FAME profiles}

Lipid extraction using our DME-based method was compared with Bligh and Dryer, and Soxhlet extractions, as shown in Fig. 2b. The B\&D method resulted in the highest raw lipid yields; extraction from dry and wet samples achieved 576.6 and $502.2 \mathrm{mg} / \mathrm{g}$ dry biomass, respectively. Our DME method extracted $152.2 \mathrm{mg}$ raw lipid per $1 \mathrm{~g}$ microalgae (dry base) during the first extraction process, which was similar to the yield obtained with a Soxhlet extraction using HE $(144.9 \mathrm{mg} / \mathrm{g})$, while the hexanebased Soxhlet extraction hardly extracted lipids. It should be noticed that, due to the simultaneous dewatering effect by DME, water content of microalgae reduced, and lipid became easier to extract after the first DME extraction process. Thus, $306.5 \mathrm{mg} / \mathrm{g}$ raw lipid was extracted by 2 nd extraction process of DME even without any entrainer addition.

The relatively highest proportion of FAMEs was obtained using the DME method (31.7\% of 1st process,
$13.0 \%$ of 2 nd process), followed by $15.4 \%$ with $B \& D$ (dry), $10.0 \%$ with B\&D (wet), and 5.3\% with Soxhlet extraction (HE). These values are consistent with the findings in previous studies [25]. In addition, significant differences were observed in FAME profiles among extraction methods, as shown in Fig. 3. All evaluated methods yielded FAME profiles containing primarily C14:0, C16:0, C16:1, C18:0, C18:1, and C18:2, which constituted 81.1-89.8\% of the total FAMEs. However, the relative amount of each lipid varied among methods. For example, C16:0 constituted $52.2 \%$ of the FAMEs obtained via B\&D (dry), while the fraction of C16:0 obtained by extraction via Benchmark B\&D (wet) was 25.0\%. Relatively higher C16:1 proportions were obtained by DME and Soxhlet (HE) extraction (22.2\% and $23.6 \%$, respectively), compared to $\mathrm{B} \& \mathrm{D}$ (dry) with $\mathrm{B} \& \mathrm{D}$ (wet) extractions $(\sim 15 \%)$. The proportion of $C 18: 1$ by $B \& D$ (wet) was $22.87 \%$, much higher than the proportion achieved with other methods. Thus, compared to Soxhlet (HE) extraction, DME method shows clear advantages for the extraction of FAMEs. The addition of ethanol into hexane did not make the solvent mixture miscible with water; thus, contact between hexane and lipids in the microalgae could not be achieved.

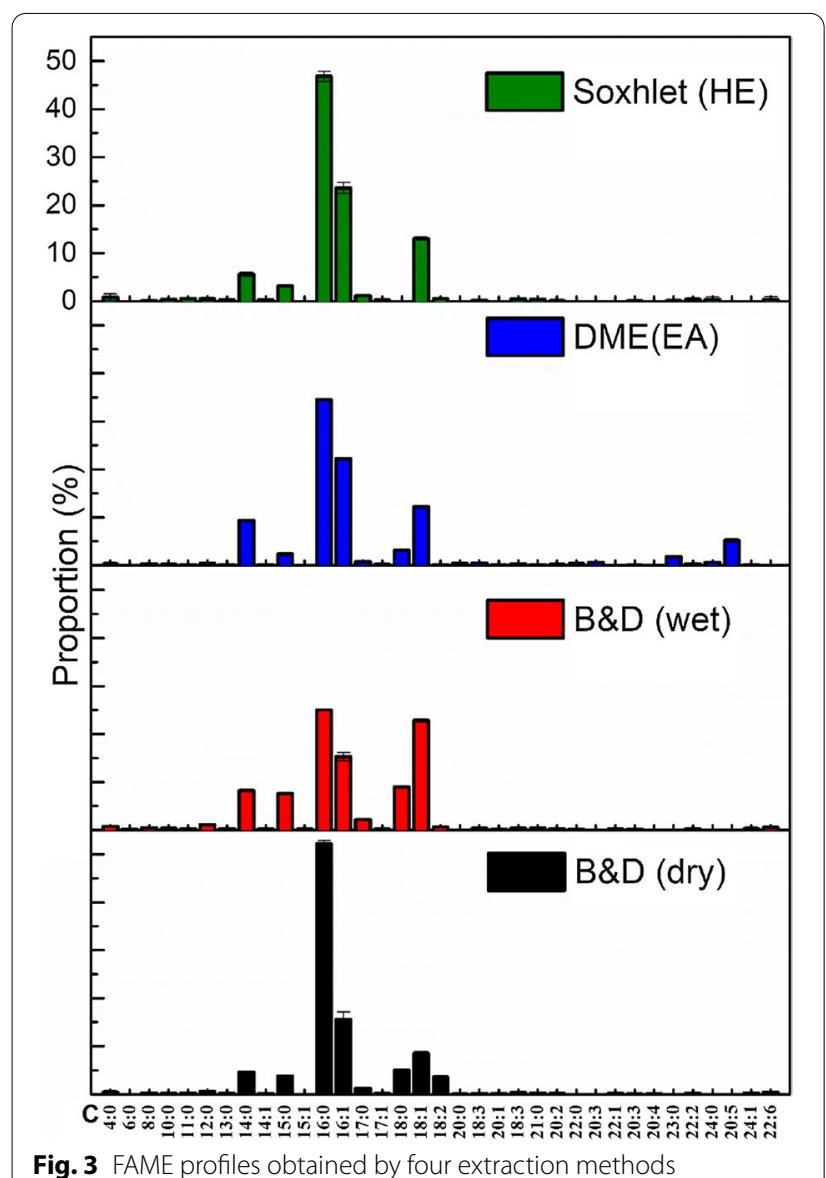


However, certain non-lipids (e.g., sugars and pigments) were extracted into the ethanol-water phase and transferred to the HE phase, comprising the extracted raw lipid.

When B\&D (dry) extraction is regarded as the benchmark for total lipid recovery $[29,46]$, DME method of 1st extraction process extracted $26.4 \%$ of the total raw lipids and $54.4 \%$ of the total FAMEs in the microalgae. Therefore, the DME preferred to extract lipid component (represented by FAME) rather than non-lipid part; otherwise, the ratio of total raw lipids and FAMEs being extracted should be the same. Although the process did not achieve complete lipid extraction, simultaneous dewatering would allow the remaining lipids to be easily recovered in the second DME extraction process, by which $53.2 \%$ of total raw lipids with $44.7 \%$ of the total FAMEs was further extracted by the 2nd process. Here, this second extraction demonstrated the diminishing returns mentioned in 2.2. Since the lipid component was preferentially extracted, FAME yields easily reached its limit with the increasing of DME dosage (1st extraction process reached to $54.4 \%$ and 2 nd extraction process accumulated to 99.1\%) and that increase rate of FAME yields slowed down with the further increasing of DME dosage was observed. Unlike it, after the 2nd extraction, there was still $20.4 \%$ of the total raw lipid remaining (it was almost all non-lipid component) and this diminishing returns on the total raw lipid was hence not obvious. Moreover, the 2nd extraction process was not indispensable, since more than half of FAMEs has been extracted in the 1st process and it is acceptable to sacrifice some extraction efficiency in exchange for low cost. The DME method achieved lipid extraction from liquid-like microalgae sample; the energy and materials cost for dewatering samples in conventional methods can be saved. Because DME is easily recycled and reused [25], DME extraction can be considered highly economical. In addition, the DME method in this study did not require cell disruption [1] via ultrasound or microwave irradiation, high-pressure homogenization, enzymatic hydrolysis, or chemical hydrolysis, while cell disruption by one or more of these processes is considered an indispensable pretreatment in other lipid extraction methods.

\section{FTIR, TG/DTA, and elemental composition}

FTIR spectra of extracted raw lipids are shown in Fig. 4. The peaks at $3007 \mathrm{~cm}^{-1}$ were consistent with olefinic $\mathrm{C}-\mathrm{H}$ stretching in unsaturated fats [47]. The peaks at $2953 \mathrm{~cm}^{-1}$ were assigned to $\mathrm{C}-\mathrm{H}$ stretches in $-\mathrm{CH}_{3}$. The strong absorption peaks at 2926 and $2855 \mathrm{~cm}^{-1}$ corresponded to $\mathrm{C}-\mathrm{H}$ stretches in $-\mathrm{CH}_{2}$. The double peaks at 2359 and $2336 \mathrm{~cm}^{-1}$ corresponded to $\mathrm{N}-\mathrm{H}$ stretching vibrations of amino groups $[48,49]$. The $\mathrm{C}=\mathrm{O}$ stretch

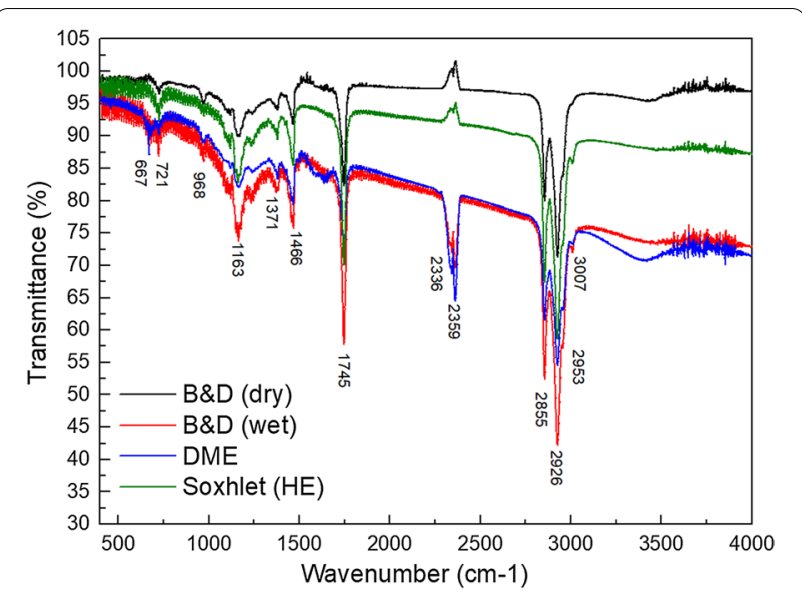

Fig. 4 FTIR spectra of lipids obtained using the four extraction methods

of an ester could be observed at $1745 \mathrm{~cm}^{-1}$. Symmetric and asymmetric bending of methyl groups resulted in peaks at 1371 and $1466 \mathrm{~cm}^{-1}$, respectively; the $\mathrm{C}-\mathrm{O}$ ester stretch was evidenced by a peak at $1163 \mathrm{~cm}^{-1}$. Peaks at $968 \mathrm{~cm}^{-1}$ corresponded to stretching vibrations of the $\mathrm{C}-\mathrm{C}$ backbone. The lipid spectra were similar, regardless of the extraction method. The only exception was that $\mathrm{N}-\mathrm{H}$ peaks $\left(2359,2336 \mathrm{~cm}^{-1}\right)$ from samples obtained by B\&D (wet) and DME methods were much stronger than those obtained by B\&D (dry) and Soxhlet (HE) methods. These findings indicated that raw lipids extracted by B\&D (wet) and DME methods contained greater levels of nitrogen.

The oxidative and thermal stabilities of extracted raw lipids are shown in Fig. 5. For each of the four raw lipid samples, mass loss could be roughly divided into three stages [50, 51]: 50\% of the mass loss occurred during the first stage with a derivative thermogravimetry peak and corresponding DTA exothermic peak at $350{ }^{\circ} \mathrm{C}$. This transition is due to the formation of alkyl radicals and their reaction with oxygen. Unsaturated lipids decomposed in this stage. In the second stage (exothermic DTA peak), a 20\% loss of mass occurred with a derivative thermogravimetry peak at $400-415{ }^{\circ} \mathrm{C}$. This can be attributed to the degradation of carbon chains and decomposition of any remaining unsaturated lipids and saturated lipids. The last exothermic stage, from 450 to $550{ }^{\circ} \mathrm{C}$, corresponded to the complete oxidation of carbonaceous residues from the first two stages. Slight differences were observed in the thermal data of the four lipid samples. A small derivative thermogravimetry peak ( $3 \%$ mass loss) at $175^{\circ} \mathrm{C}$ was present in the thermogram of raw lipids obtained from B\&D (dry). This exothermic peak can be attributed to the initial degradation of esters 

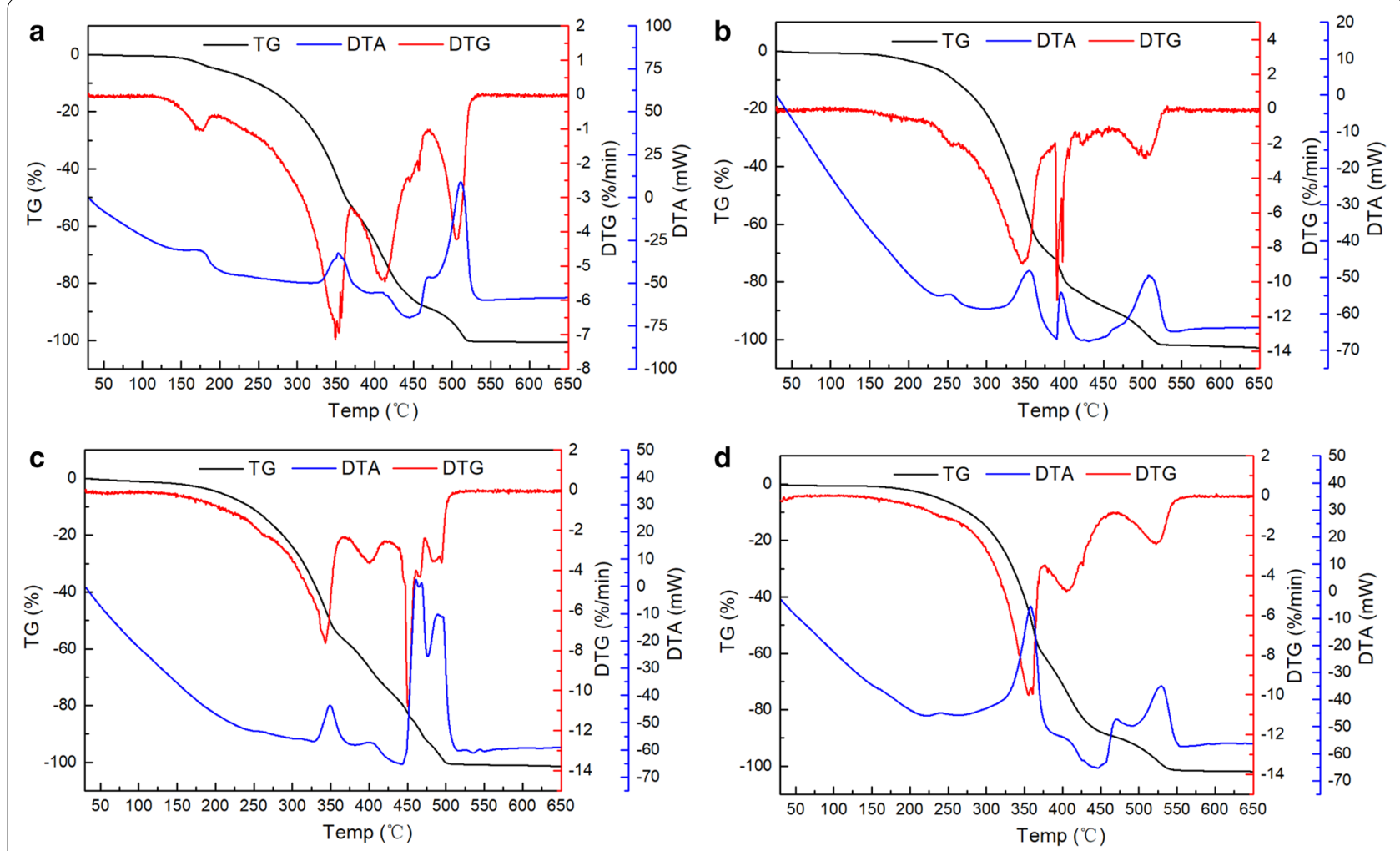

Fig. 5 TG/DTA thermograms of raw lipids obtained via a B\&D (dry), b B\&D (wet), c DME, and $\mathbf{d}$ Soxhlet (HE) extraction processes

by the action of oxygen, rather than the evaporation of lipids [52].

Additional file 1: Table $\mathrm{S} 2$ shows the $\mathrm{C} / \mathrm{H} / \mathrm{N}$ compositions of the extracted raw lipids. Nitrogen content is an important metric when using extracted lipids as biofuel; low $\mathrm{N}$ content is preferable for combustion [53]. In this study, the $\mathrm{N}$ contents in extracted lipids ranged from 0.09 to $0.23 \%$, among the various methods. The highest $\mathrm{N}$ content of $0.23 \%$ was obtained by DME, which was consistent with the FTIR data. The B\&D (wet) extraction yielded lipids relatively high in $C$ (76.21\%) and low in $\mathrm{O}$ (11.26\%). This can be attributed to the isolation of a wide range of components from microalgae [29].

\section{Trace metal analyses}

Trace metals in biodiesel can lead to metallic corrosion during transport and storage, enhanced pollutant emission, and engine deterioration [54, 55]. Relative to the blank (ultrapure water), trace inductively coupled plasma mass spectrometry analyses indicated the presence of $\mathrm{Fe}, \mathrm{Ni}, \mathrm{Cu}, \mathrm{Zn}, \mathrm{Sr}, \mathrm{Ba}, \mathrm{Mg}, \mathrm{K}$, and $\mathrm{Na}$ in the extracted raw lipids, as shown in Table 1. Ca and $\mathrm{Si}$, which were reported by Kanda et al. [29], were not found in our microalgae samples. Trace metals in this study were derived primarily from the cultivation broth. The concentrations of $\mathrm{Mg}, \mathrm{Na}, \mathrm{K}$, and Fe were particularly high. The Mg content in samples extracted using our DME-based method was 66\%oo. This indicates that further purification would be required to remove trace metals before using the extracted materials as vehicle fuel. Raw lipids extracted using the B\&D (wet) method will likely require a similar treatment; the sum of $\mathrm{Fe}, \mathrm{Mg}$, and $\mathrm{Na}$ contents was $19 \%$.

\section{Conclusions}

A mixture of ethanol and acetone was used as an entrainer to significantly improve the yield of lipids extracted from flocculation-harvested microalgae with DME. Addition of ethanol or acetone to DME enhanced its miscibility with water and improved lipid yields by factors of 4.0 and 6.4, respectively. Optimal conditions for lipid extraction were: $30 \mathrm{~min}, 4.2 \mathrm{~mL}$ DME per $1 \mathrm{~mL}$ microalgae, and an entrainer dosage of $8 \%$ at an ethanol:acetone ratio of 1:2. Under these optimal conditions, a comparison of our DME method (entrainer) against conventional $B \& D$ and Soxhlet extraction methods revealed that the DME method of 1st process extracted $26.4 \%$ of the total raw lipids with $54.4 \%$ of the total FAMEs in microalgae, and remnants could be 
Table 1 Trace metals in extracted raw lipids

\begin{tabular}{|c|c|c|c|c|c|c|c|c|c|c|}
\hline & & $\begin{array}{l}\mathrm{Fe} \\
(\% \circ)\end{array}$ & $\begin{array}{l}\mathrm{Ni} \\
(\% \circ)\end{array}$ & $\begin{array}{l}\mathrm{Cu} \\
(\% \circ o)\end{array}$ & $\begin{array}{l}\mathrm{Zn} \\
(\% \circ)\end{array}$ & $\begin{array}{l}\mathrm{Sr} \\
(\% \circ)\end{array}$ & $\begin{array}{l}\mathrm{Ba} \\
(\% \circ)\end{array}$ & $\begin{array}{l}\mathrm{Mg} \\
(\% \circ)\end{array}$ & $\begin{array}{l}\mathrm{K} \\
(\% \circ)\end{array}$ & $\begin{array}{l}\mathrm{Na} \\
(\% \circ)\end{array}$ \\
\hline \multirow[t]{2}{*}{ B\&D (dry) } & Mean & 0.416 & 0.029 & 0.049 & 0.041 & 0.326 & 0.200 & 2.067 & - & 4.500 \\
\hline & Variance & 0.015 & 0.001 & 0.003 & 0.007 & 0.001 & 0.002 & 0.173 & - & 0.929 \\
\hline \multirow[t]{2}{*}{ DME } & Mean & 0.824 & 0.075 & 0.746 & 0.353 & 0.005 & 0.013 & 66.633 & 1.867 & 1.833 \\
\hline & Variance & 0.023 & 0.002 & 0.011 & 0.018 & 0.000 & 0.002 & 0.416 & 0.000 & 0.100 \\
\hline \multirow[t]{2}{*}{ Soxhlet (HE) } & Mean & 0.380 & 0.044 & 0.030 & 0.056 & 0.015 & 0.067 & 3.067 & - & - \\
\hline & Variance & 0.011 & 0.001 & 0.001 & 0.008 & 0.000 & 0.003 & 0.520 & - & - \\
\hline \multirow[t]{2}{*}{ B\&D (wet) } & Mean & 3.334 & 0.388 & 0.082 & 0.173 & 0.042 & 0.043 & 7.933 & 0.533 & 7.867 \\
\hline & Variance & 0.056 & 0.006 & 0.010 & 0.015 & 0.001 & 0.001 & 0.058 & 0.115 & 0.115 \\
\hline
\end{tabular}

easily recovered by a 2 nd extraction process. Among all evaluated methods, the proportion of FAMEs was highest using our DME-based method. Finally, the extracted raw lipids obtained by each method were characterized by thermal analyses and FTIR spectrometry. Enhanced nitrogen levels in lipids extracted by B\&D (wet) and our DME-based method, as indicated by strong $\mathrm{N}-\mathrm{H}$ vibrations in FTIR spectra, were confirmed by $\mathrm{C} / \mathrm{H} / \mathrm{N}$ analyses. TG/DTA data indicated that extracted lipids began to decompose at $150{ }^{\circ} \mathrm{C}$, with the final decomposition temperature varying from 500 to $535{ }^{\circ} \mathrm{C}$. Inductively coupled plasma analyses showed traces of $\mathrm{Fe}, \mathrm{Ni}$, $\mathrm{Cu}, \mathrm{Zn}, \mathrm{Sr}, \mathrm{Ba}, \mathrm{Mg}, \mathrm{K}$, and $\mathrm{Na}$ in the extracted raw lipid samples. DME-based extraction resulted in particularly high levels of $\mathrm{Mg}$ in the produced lipids, indicating that further purification would be required prior to the use of these extracted lipids as biofuel.

\section{Materials and methods}

\section{Microalgae cultivation and pretreatment}

Marine microalgae strain $N$. oculata was obtained from the Microbial Culture Collection at the National Institute for Environmental Studies (Tsukuba, Japan). The strain is a genus of unicellular, oval-shaped, and non-mobile marine microalgae with a cell diameter of 3-8 $\mu \mathrm{m}$. The algae were cultivated in ESM medium [56], as shown in Additional file 1: Table S1, in 20-L bucket photo-bioreactors at $20 \pm 2{ }^{\circ} \mathrm{C}$ with light/dark cycles of $12 \mathrm{~h} / 12 \mathrm{~h}$. After 2 weeks of cultivation, the microalgae entered the stationary phase and were thickened by induced flocculation using $60 \mathrm{mg} / \mathrm{L} \mathrm{AlCl}_{3}$.

The biomass concentrations of microalgae before and after flocculation were measured. Samples were filtered through a vacuum filter with pre-weighted glass filter paper (GF/C, $1.2 \mathrm{um}, 4.7 \mathrm{~cm}$; Whatman plc, MA, USA) and were washed several times with deionized water. The filtrate was dried in an oven at $105{ }^{\circ} \mathrm{C}$ for $24 \mathrm{~h}$ to achieve a constant weight and cooled to room temperature in a desiccator prior to weighing. This process was repeated in triplicate. The biomass concentration of the original microalgae was $0.64 \pm 0.01 \mathrm{~g} / \mathrm{L}$; it increased to $18.3 \pm 0.79 \mathrm{~g} / \mathrm{L}$ following flocculation. Thus, the flocculated samples for the lipid extraction were composed of water $(948.3 \mathrm{~g} / \mathrm{L})$, microalgae $(18.3 \mathrm{~g} / \mathrm{L}$ D.W.) and salts $(33.4 \mathrm{~g} / \mathrm{L}$, from cultivation medium of sea water, Additional file 1: Table S1).

\section{DME extraction}

\section{Device description and experimental procedure}

As shown in graphical abstract, the DME extraction system was composed of five parts: a liquefied DME storage vessel (vessel 1, TVS-1-100, $500 \mathrm{~cm}^{3}$, Taiatsu Techno Corp., Saitama, Japan), a vessel to measure DME (vessel 2, $100 \mathrm{~cm}^{3}$, HPG-96-3, $26.5 \mathrm{~mm} \phi \times 238 \mathrm{~mm}$, Taiatsu Techno Corp.), a vessel for lipid extraction (vessel 3, 100 $\mathrm{cm}^{3}$, HPG-96-3, $26.5 \mathrm{~mm} \phi \times 238 \mathrm{~mm}$, Taiatsu Techno Corp.), a vessel for separating liquid from solvents (vessel 4, $100 \mathrm{~cm}^{3}$, HPG-96-3, $26.5 \mathrm{~mm} \phi \times 238 \mathrm{~mm}$, Taiatsu Techno Corp.), and a moisture trap column of $\mathrm{CaCl}_{2}$ (HPG-10-5, $11.6 \mathrm{~mm} \phi \times 190 \mathrm{~mm}$, Taiatsu Techno Corp.).

Flocculation-thickened microalgae were loaded onto an extraction column containing a cellulose extraction thimble (glass fiber, $\phi 25 \times 100 \mathrm{~mm}$, Whatman, Maidstone, United Kingdom). The entire assembly was placed in vessel 3 after the entrainer had been added. A specified amount of liquefied DME was pushed from vessel 1 to vessel 2 by $\mathrm{N}_{2}$ gas (ZERO-A, Sumitomo Seika Chemicals Company, Ltd., Japan). The measured volume of DME in vessel 2 was then allowed to flow into vessel 3 . After several minutes of extraction, only the liquid phase in vessel 3 was transferred to vessel 4 . DME in the liquid evaporated with pressure relief and the raw lipids were deposited on the upper surface of the residual liquid (entrainer, water, and salts). The separated raw lipids were dissolved in $5.0 \mathrm{~mL}$ of chloroform (Guaranteed Reagent, Wako Co., Ltd.) and filtered through a $0.45-\mu \mathrm{m}$ membrane filter (DISMIC-13HP, Advantech Co., Ltd., Japan). The 
chloroform was then removed by a stream of nitrogen gas (Nitrogen Termovap Sample Concentrator, Tokyo Rikakikai Co., Ltd., Japan); the recovered raw lipid concentrate was weighed and stored below $0{ }^{\circ} \mathrm{C}$.

\section{Entrainer screening}

Four potential entrainers (Table 2), miscible in water at any ratio, were evaluated for their efficiency in lipid extraction using liquid DME. In each experiment, $25 \mathrm{~mL}$ of DME was used to extract the lipids from $8 \mathrm{~mL}$ of flocculation-thickened microalgae $(18.3 \pm 0.79 \mathrm{~g} / \mathrm{L})$ over $30 \mathrm{~min}$. As an entrainer, $2.5 \mathrm{~mL}$ of ethanol, DMSO, THF, or acetone (Guaranteed Reagent, Wako Co., Ltd.) was added. The results were compared with those obtained with a blank mixture that did not include an entrainer.

\section{Effects of extraction time, DME dosage, entrainer dosage, and entrainer ethanol:acetone ratio}

Based on the data obtained in Sect. "Entrainer screening", ethanol and acetone were selected for further experiments. To study the effects of extraction time, the volume ratio of DME:microalgae:ethanol:acetone was fixed at 25:8:2:2 and extraction time was varied from 10 to $45 \mathrm{~min}$. To study the effects of DME dosage, the extraction time was fixed at $45 \mathrm{~min}$ and the amount of DME:entrainer was varied from $25 \mathrm{~mL}$ per $16 \mathrm{~mL}$ microalgae to $25 \mathrm{~mL}$ per $4 \mathrm{~mL}$ microalgae at a constant DME:ethanol:acetone ratio of 25:2:2. To study the effects of entrainer dosage, the extraction time and ratio of DME to microalgae were fixed at $45 \mathrm{~min}$ and $25: 8$, respectively, over a range of DME:ethanol:acetone from 25:0.5:0.5 to 25:3:3. To study the effects of ethanol:acetone ratio, $8 \mathrm{~mL}$ of microalgae were treated with $25 \mathrm{~mL}$ DME:entrainer for $45 \mathrm{~min}$ using a total of $5 \mathrm{~mL}$ of entrainer (ethanol + acetone) and ethanol:acetone ratios of 1:4, 1:3, 1:2, 1:1, 2:1, $3: 1$, or $4: 1$.

\section{Bligh and Dyer extraction}

The Bligh and Dyer method [57] is a classical method for lipid extraction, which is regarded as a reference point for determining the total lipid content of microalgae [29]. In this study, the Bligh and Dyer method was applied to both flocculation-thickened microalgae and completely dried microalgae (heated at $105{ }^{\circ} \mathrm{C}$ for $24 \mathrm{~h}$ ). For the dried microalgae, $5.0 \mathrm{~mL}$ of methanol (Guaranteed Reagent, Wako Co., Ltd.), $2.5 \mathrm{~mL}$ of chloroform (Guaranteed Reagent, Wako Co., Ltd.), and $2.0 \mathrm{~mL}$ of pure water were mixed in a centrifuge tube with a dried sample that had been obtained from $10 \mathrm{~mL}$ of flocculation-thickened microalgae. The mixture was crushed using a homogenizer (T25, IKA Co., Ltd., Germany) at 10,000 rpm for $5 \mathrm{~min}$ and mixed using a Vortex Genie (SI-0236, SI Co., USA) for $5 \mathrm{~min}$. Then, $2.5 \mathrm{~mL}$ of chloroform and $2.5 \mathrm{~mL}$ of pure water were added to the tube with an additional 2 min of mixing. After the sample had been centrifuged at 3,000 rpm (2410, Kubota Co., Ltd., Japan) for $5 \mathrm{~min}$, it was divided into three layers from top to bottom: watermethanol, microalgae, and lipid-chloroform. Chloroform was recovered from the bottom layer; the resulting lipidrich mixture was filtered through a $0.45-\mu \mathrm{m}$ membrane. Most solvent was removed using a rotary evaporator at $40^{\circ} \mathrm{C}$ under vacuum. The remaining solvent was removed by evaporation with a stream of nitrogen. The resulting raw lipids were weighed and stored below $0{ }^{\circ} \mathrm{C}$. Flocculation-thickened microalgae were processed using the same modified Bligh and Dyer method, except no additional water was added. The original sample volume was $5 \mathrm{~mL}$.

\section{Soxhlet extraction}

Soxhlet extraction is commonly used to extract lipids from biomass [58]. Two solvents were evaluated in this study: hexane and hexane-ethanol (HE). For each experiment, $20 \mathrm{~mL}$ of flocculation-thickened microalgae were place in a cellulose extraction thimble (glass fiber, $\phi 28 \times 100 \mathrm{~mm}$, Whatman) along with $100 \mathrm{~mL}$ hexane or $100 \mathrm{~mL}$ of HE (1:1 v:v). The thimble was then loaded into a Soxhlet extraction device. Each extraction was run for $24 \mathrm{~h}$ to ensure completeness; resulting extracts were transferred to a flask where the solvent was removed by

Table 2 Characteristics of solvents used in this study

\begin{tabular}{|c|c|c|c|c|c|c|}
\hline & \multirow[t]{2}{*}{ Water } & \multirow[t]{2}{*}{ DME } & \multicolumn{4}{|c|}{ Entrainers } \\
\hline & & & Ethanol & DMSO & THF & Acetone \\
\hline Formula & $\mathrm{H}_{2} \mathrm{O}$ & $\mathrm{C}_{2} \mathrm{H}_{6} \mathrm{O}$ & $\mathrm{C}_{2} \mathrm{H}_{6} \mathrm{O}$ & $\mathrm{C}_{2} \mathrm{H}_{6} \mathrm{OS}$ & $\mathrm{C}_{4} \mathrm{H}_{8} \mathrm{O}$ & $\mathrm{C}_{3} \mathrm{H}_{6} \mathrm{O}$ \\
\hline Molecular weight & 18.02 & 46.07 & 46.07 & 78.13 & 72.11 & 58.08 \\
\hline Density (g/mL) & 0.998 & 1.970 & 0.789 & 1.092 & 0.883 & 0.785 \\
\hline Melting point $\left({ }^{\circ} \mathrm{C}\right)$ & 0.0 & -138.0 & -114.1 & 18.4 & -108.4 & -94.7 \\
\hline Boiling point $\left({ }^{\circ} \mathrm{C}\right)$ & 100.0 & -25.0 & 78.5 & 189.0 & 65.0 & 56.1 \\
\hline Dielectric constant & 78.54 & 5.02 & 24.60 & 47.00 & 7.52 & 21.01 \\
\hline
\end{tabular}


rotary evaporation under vacuum. The extracts were then re-dissolved in $10 \mathrm{~mL}$ of chloroform and filtered through a $0.45-\mu \mathrm{m}$ membrane. The solvent was then removed completely by evaporation with a stream of nitrogen. The resulting raw lipids were weighed and stored below $0{ }^{\circ} \mathrm{C}$.

\section{Extract characterization}

The extracted raw lipid contains not only the lipid component which is the raw material of biodiesel, but also impurities (sterols, proteins, hydrocarbons, pigments...). And the lipid component in extracted raw lipid cannot be directly quantified, it must be pretreated, and the extracted raw lipids were converted into fatty acid methyl esters (FAMEs) by transesterification. Specifically, the raw lipids were re-dissolved in $5 \mathrm{~mL}$ of dichloromethane (Guaranteed Reagent, Wako Co., Ltd.) and methylated by mixture with $2 \mathrm{~mL}$ of $14 \% \mathrm{BF}_{3}$-methanol solution (First Grade, Wako Co., Ltd.) at $65{ }^{\circ} \mathrm{C}$ for $40 \mathrm{~min}$. After the mixture had cooled to room temperature, the dichloromethane layer containing FAMEs was separated by addition of $4 \mathrm{~mL}$ of saturated aqueous $\mathrm{NaCl}$ solution (Guaranteed Reagent, Wako Co., Ltd.). After the dichloromethane layer had been isolated, the solvent was evaporated using a stream of nitrogen. The recovered FAMEs were then redissolved in a specified amount of dichloromethane for gas chromatography-mass spectrometry analysis (GC/ MS-QP2010 Plus, Shimadzu Corp., Kyoto, Japan) using a 37-component FAME mixture (Sigma-Aldrich Japan, Co., Ltd., Tokyo, Japan) as a standard. The FAME proportions and FAME yields were calculated using the formula given below:

$$
\begin{aligned}
& \text { FAMEproportions }(\%)=\frac{\text { WeightofFAMEs }}{\text { Weightofrawlipid }} \times 100 \%, \\
& \text { FAMEyields }(\mathrm{mg} / \text { gD.B. })=\frac{\text { WeightofFAMEs }}{\text { Weightofdrymicroalgalbiomass }}
\end{aligned}
$$

The carbon, hydrogen, and nitrogen contents of the extracted raw lipids were determined using an elemental analyzer (Micro Corder JM10, J-science Labo Co., Ltd.). FTIR spectra of the lipids were obtained using a Shimadzu FTIR-8400 spectrometer. Lipid samples were dropped onto a $\mathrm{KBr}$ tablet (Infrared spectrophotometry grade, Wako Co., Ltd.) and spectra were acquired from 400 to $4000 \mathrm{~cm}^{-1}$. TG and TG-DTA were performed using a Rigaku ThermoPlus TG8110 with an air flow of $100 \mathrm{~mL} / \mathrm{min}$ and a heating rate of $10^{\circ} \mathrm{C} / \mathrm{min}$ from 20 to $650^{\circ} \mathrm{C}$.

Trace elements in the extracted lipids were qualitatively analyzed by inductively coupled plasma mass spectrometry (XSeries 2, Thermo Fisher Scientific Co.), and then quantitatively analyzed by inductively coupled plasma atomic emission spectroscopy (ICAP-7000, Thermo Fisher Scientific Co.). The extracted lipids ( $25 \mathrm{mg}$ ) were first digested in a mixture of $0.75 \mathrm{~mL} \mathrm{HNO}_{3}$ (Guaranteed Reagent, 69\%, Wako Co., Ltd.), $0.25 \mathrm{~mL} \mathrm{H}_{2} \mathrm{O}_{2}$ (Guaranteed Reagent, 30\%, Wako Co., Ltd.), and $15 \mathrm{~mL} \mathrm{H}_{2} \mathrm{O}$ (Ultrapure Water, Wako Co., Ltd.) in a microwave digestion system (ETHOS One, Milestone Inc., USA). The mixtures were digested for $10 \mathrm{~min}$ at $100{ }^{\circ} \mathrm{C}$ at $500 \mathrm{~W}$ and then $10 \mathrm{~min}$ at $200{ }^{\circ} \mathrm{C}$ at $1000 \mathrm{~W}$. The resulting clear digestate was collected and diluted for analysis.

\section{Statistical analysis}

All data are presented as the mean \pm standard deviation of independent experiments conducted in triplicate. Data were subjected to analysis of variance by Microsoft Office Excel 2010; differences between means were assessed by Fisher's least significant difference test. Statistical significance was set at $p<0.05$.

\section{Supplementary Information}

The online version contains supplementary material available at https://doi. org/10.1186/s13068-020-01871-0.

Additional file 1: Table S1. The component of ESM for cultivating Nannochloropsis oculata. Table S2. The Elemental composition of extracted raw lipids by the 4 methods. Figure $\mathbf{S 1}$. Solid content of microalgae after lipid extraction by DME with 4 kinds of additive agents added. Figure S2. FAMEs composition of extracted lipid with 4 kinds of additive agents added, a) blank, b) ethanol, c) DMSO, d) acetone, e) THF.

\section{Acknowledgements}

We thank the staff of NIES for providing microalgae species. This research was conducted in part at the Division of Green Chemical and Environmental Engineering, Advanced Research Institute, Katsura-Int'tech Center, Graduate School of Engineering, Kyoto University.

\section{Authors' contributions}

QW: formal analysis, investigation, writing—original draft preparation. KO: writing — review and editing, conceptualization. MT: funding acquisition, project administration

Funding

Not applicable.

Availability of data and materials

All data generated or analyzed during this study are included in its Additional files.

Ethical approval and consent to participate

Not applicable.

Consent for publication

Not applicable.

Competing interests

The authors declare that they have no competing interest.

Received: 9 October 2020 Accepted: 28 December 2020 Published online: 09 January 2021 


\section{References}

1. Dong T, Knoshaug EP, Pienkos PT, Laurens LM. Lipid recovery from wet oleaginous microbial biomass for biofuel production: a critical review. Appl Energy. 2016;177:879-95

2. Du Y, Schuur B, Kersten SR, Brilman DW. Multistage wet lipid extraction from fresh water stressed Neochloris oleoabundans slurry-experiments and modelling. Algal Res. 2018;31:21-30.

3. Ansari FA, Gupta SK, Shriwastav A, Guldhe A, Rawat I, Bux F. Evaluation of various solvent systems for lipid extraction from wet microalgal biomass and its effects on primary metabolites of lipid-extracted biomass. Environ Sci Pollut Res. 2017;24(18):15299-307.

4. Williams PJLB, Laurens LM. Microalgae as biodiesel and biomass feedstocks: review and analysis of the biochemistry, energetics and economics. Energy Environ Sci. 2010;3(5):554-90.

5. Angles E, Jaouen P, Pruvost J, Marchal L. Wet lipid extraction from the microalga Nannochloropsis sp.: disruption, physiological effects and solvent screening. Algal Res. 2017;21:27-34.

6. Ghasemi Naghdi F, González González LM, Chan W, Schenk PM. Progress on lipid extraction from wet algal biomass for biodiesel production. Microb Biotechnol. 2016:9(6):718-26.

7. Qiu C, He Y, Huang Z, Li S, Huang J, Wang M, Chen B. Lipid extraction from wet Nannochloropsis biomass via enzyme-assisted three phase partitioning. Biores Technol. 2019;284:381-90.

8. Sirisuk P, Sunwoo I, Kim SH, Awah CC, Ra CH, Kim JM, et al. Enhancement of biomass, lipids, and polyunsaturated fatty acid (PUFA) production in Nannochloropsis oceanica with a combination of single wavelength light emitting diodes (LEDs) and low temperature in a three-phase culture system. Biores Technol. 2018;270:504-11.

9. Shuba ES, Kifle D. Microalgae to biofuels: 'Promising'alternative and renewable energy, review. Renew Sustain Energy Rev. 2018;81:743-55.

10. Patel A, Arora N, Pruthi $V$, Pruthi PA. A novel rapid ultrasonicationmicrowave treatment for total lipid extraction from wet oleaginous yeast biomass for sustainable biodiesel production. Ultrason Sonochem. 2019;51:504-16.

11. Seo $Y H$, Sung M, Oh YK, Han Jl. Lipid extraction and esterification for microalgae-based biodiesel production using pyrite (FeS2). Biores Technol. 2015;191:420-5

12. Garzon-Sanabria AJ, Davis RT, Nikolov ZL. Harvesting Nannochloris oculata by inorganic electrolyte flocculation: effect of initial cell density, ionic strength, coagulant dosage, and media pH. Biores Technol. 2012;118:418-24

13. Lam MK, Lee KT. Microalgae biofuels: a critical review of issues, problems and the way forward. Biotechnol Adv. 2012;30(3):673-90.

14. Singh G, Patidar SK. Microalgae harvesting techniques: a review. J Environ Manag. 2018;217:499-508.

15. Barros Al, Gonçalves AL, Simões M, Pires JC. Harvesting techniques applied to microalgae: a review. Renew Sustain Energy Rev. 2015;41:1489-500.

16. Tang S, Qin C, Wang H, Li S, Tian S. Study on supercritical extraction of lipids and enrichment of DHA from oil-rich microalgae. J Supercritic Fluids. 2011:57(1):44-9.

17. Sheng J, Vannela R, Rittmann BE. Evaluation of methods to extract and quantify lipids from Synechocystis PCC 6803. Biores Technol. 2011;102(2):1697-703.

18. Wu J, Alam MA, Pan Y, Huang D, Wang Z, Wang T. Enhanced extraction of lipids from microalgae with eco-friendly mixture of methanol and ethyl acetate for biodiesel production. J Taiwan Inst Chem Eng. 2017;71:323-9.

19. Lardon L, Helias A, Sialve B, Steyer J-P, Bernard O. Life-cycle assessment of biodiesel production from microalgae. Environ Sci Technol. 2009:43(17):6475-81.

20. Lakshmikandan M, Murugesan AG, Wang S, Abomohra AEF, Jovita PA, Kiruthiga S. Sustainable biomass production under $\mathrm{CO}_{2}$ conditions and effective wet microalgae lipid extraction for biodiesel production. J Clean Prod. 2020:247:119398.

21. Sánchez-Bayo A, López-Chicharro D, Morales V, Espada JJ, Puyol D, Martínez F, et al. Biodiesel and biogas production from /sochrysis galbana using dry and wet lipid extraction: a biorefinery approach. Renew Energy. 2020;146:188-95

22. Cheng J, Yu T, Li T, Zhou J, Cen K. Using wet microalgae for direct biodiesel production via microwave irradiation. Biores Technol. 2013:131:531-5.
23. Sander K, Murthy GS. Life cycle analysis of algae biodiesel. Int J Life Cycle Assess. 2010;15(7):704-14.

24. Goto M, Kanda H, Machmudah S. Extraction of carotenoids and lipids from algae by supercritical $\mathrm{CO}_{2}$ and subcritical dimethyl ether. J Supercritic Fluids. 2015;96:245-51.

25. Wang Q, Oshita K, Nitta T, Takaoka M. Evaluation of a sludge-treatment process comprising lipid extraction and drying using liquefied dimethyl ether. Environ Technol. 2020. https://doi.org/10.1080/09593 330.2020 .1730982$.

26. Tallon S, Fenton K. The solubility of water in mixtures of dimethyl ether and carbon dioxide. Fluid Phase Equilib. 2010;298(1):60-6.

27. Oshita K, Takaoka M, Nakajima Y, Morisawa S, Kanda H, Makino H, Takeda $\mathrm{N}$. Characteristics of biosolids in dimethyl ether dewatering method. Water Environ Res. 2012;84(2):120-7.

28. Oshita K, Toda S, Takaoka M, Kanda H, Fujimori T, Matsukawa K, Fujiwara T. Solid fuel production from cattle manure by dewatering using liquefied dimethyl ether. Fuel. 2015;159:7-14.

29. Kanda H, Hoshino R, Murakami K, Zheng Q, Goto M. Lipid extraction from microalgae covered with biomineralized cell walls using liquefied dimethyl ether. Fuel. 2020;262:116590.

30. Li P, Kanda H, Makino $H$. Simultaneous production of bio-solid fuel and bio-crude from vegetal biomass using liquefied dimethyl ether. Fuel. 2014;116:370-6.

31. Kanda H, Li P. Simple extraction method of green crude from natural blue-green microalgae by dimethyl ether. Fuel. 2011;90(3):1264-6.

32. Nerome H, Ito M, Machmudah S, Kanda H, Goto M. Extraction of phytochemicals from saffron by supercritical carbon dioxide with water and methanol as entrainer. J Supercritic Fluids. 2016;107:377-83.

33. Gadkari PV, Balarman M, Kadimi US. Polyphenols from fresh frozen tea leaves (Camellia assamica L.) by supercritical carbon dioxide extraction with ethanol entrainer-application of response surface methodology. J Food Sci Technol. 2015;52(2):720-30.

34. Babadi FE, Boonnoun P, Nootong K, Powtongsook S, Goto M, Shotipruk A. Identification of carotenoids and chlorophylls from green algae Chlorococcum humicola and extraction by liquefied dimethyl ether. Food Bioprod Process. 2020:123:296-303.

35. Subratti A, Lalgee $L$, Jalsa NK. Liquified dimethyl ether (DME): a green solvent for the extraction of hemp (Cannabis sativa L.) seed oil. Sustain Chem Pharm. 2019;12:100144.

36. Subratti A, Lalgee LJ, Jalsa NK. Efficient extraction of black cumin (Nigella sativa L.) seed oil containing thymol, using liquefied dimethyl ether (DME). J Food Process Preserv. 2019:43(4):e13913.

37. Li P, Sakuragi K, Makino H. Extraction techniques in sustainable biofuel production: A concise review. Fuel Process Technol. 2019;193:295-303.

38. Khoo KS, Chew KW, Yew GY, Leong WH, Chai YH, Show PL, Chen WH. Recent advances in downstream processing of microalgae lipid recovery for biofuel production. Biores Technol. 2020;304:122996.

39. Engdahl A, Nelander B. Intermolecular vibrations of the dimethyl etherwater complex. A matrix isolation study. J Chem Soc Faraday Trans. 1992;88(2):177-82.

40. De Jesus SS, Ferreira GF, Moreira LS, Maciel MRW, Maciel Filho R. Comparison of several methods for effective lipid extraction from wet microalgae using green solvents. Renew Energy. 2019;143:130-41.

41. Sada E, Morisue T, Miyahara K. Salt effects on vapor-liquid equilibrium of tetrahydrofuran-water system. J Chem Eng Data. 1975;20(3):283-7.

42. Mitra M, Mishra S. A comparative analysis of different extraction solvent systems on the extractability of eicosapentaenoic acid from the marine eustigmatophyte Nannochloropsis oceanica. Algal Res. 2019;38:101387.

43. Wu C, Xiao Y, Lin W, Zhu J, De la Hoz Siegler H, Zong M, Rong J. Surfactants assist in lipid extraction from wet Nannochloropsis sp. Biores Technol. 2017;243:793-9.

44. Shin HY, Ryu JH, Bae SY, Crofcheck C, Crocker M. Lipid extraction from Scenedesmus sp. microalgae for biodiesel production using hot compressed hexane. Fuel. 2014:130:66-9.

45. Taher H, Al-Zuhair S, Al-Marzouqi AH, Haik Y, Farid M. Effective extraction of microalgae lipids from wet biomass for biodiesel production. Biomass Bioenergy. 2014;66:159-67.

46. De Souza Silva APF, Costa MC, Lopes AC, Neto EFA, Leitao RC, Mota CR, dos Santos AB. Comparison of pretreatment methods for total lipids extraction from mixed microalgae. Renew Energy. 2014;63:762-6. 
47. Chiplunkar PP, Pratap AP. Utilization of sunflower acid oil for synthesis of alkyd resin. Prog Org Coat. 2016;93:61-7.

48. Nandiyanto ABD, Oktiani R, Ragadhita R. How to read and interpret FTIR spectroscope of organic material. Indones J Sci Technol. 2019;4(1):97-118

49. Huw Aubrey T. 2009. Novel approaches towards phosphorous containing macrocycles. PhD Thesis, Cardiff University.

50. Dos Santos Politi JR, de Matos PRR, Sales MJA. Comparative study of the oxidative and thermal stability of vegetable oils to be used as lubricant bases. J Therm Anal Calorim. 2013;111(2):1437-42.

51. Raba DN, Chambre DR, Copolovici DM, Moldovan C, Copolovici LO. The influence of high-temperature heating on composition and thermooxidative stability of the oil extracted from Arabica coffee beans. PLoS ONE. 2018. https://doi.org/10.1371/journal.pone.0200314.

52. Eychenne V, Mouloungui Z, Gaset A. Thermal behavior of neopentylpolyol esters: comparison between determination by TGA-DTA and flash point. Thermochim Acta. 1998;320(1-2):201-8.

53. Pimentel D, PatzekTW. Biofuels, solar and wind as renewable energy systems. Benefits and risks. New York: Springer; 2008.

54. Machmudah S, Winardi S, Kanda H, Goto M. Sub-and supercritical fluids extraction of phytochemical compounds from Eucheuma cottonii and Gracilaria sp. Chem Eng Trans. 2017;56:1291-6.
55. Almeida ES, Richter EM, Munoz RA. On-site fuel electroanalysis: determination of lead, copper and mercury in fuel bioethanol by anodic stripping voltammetry using screen-printed gold electrodes. Anal Chim Acta. 2014;837:38-43.

56. Tsuzuki M, Okada K, Isoda H, Hirano M, Odaka T, Saijo H, et al. Physiological properties of photoautotrophic microalgae and cyanobacteria relevant to industrial biomass production. Mar Biotechnol. 2019;21(3):406-15.

57. Bligh EG, Dyer WJ. A rapid method of total lipid extraction and purification. Can J Biochem Physiol. 1959:37(8):911-7.

58. Nor Afifah S, Darah I, Shaida Fariza S, Jain Nordin MM, Nurul Aili Z, AliShtayeh MS, et al. Soxhlet extraction of solid matrices: an outdated technique with a promising innovative future. J Appl Sci. 1998;10(23):265-71.

\section{Publisher's Note}

Springer Nature remains neutral with regard to jurisdictional claims in published maps and institutional affiliations.
Ready to submit your research? Choose BMC and benefit from:

- fast, convenient online submission

- thorough peer review by experienced researchers in your field

- rapid publication on acceptance

- support for research data, including large and complex data types

- gold Open Access which fosters wider collaboration and increased citations

- maximum visibility for your research: over 100M website views per year

At BMC, research is always in progress.

Learn more biomedcentral.com/submissions 